\title{
Impact of the COVID-19 pandemic on phase 2 cardiac rehabilitation patients in Japan
}

\author{
Asami Ogura ${ }^{1,2,3} \cdot$ Kazuhiro P. Izawa $^{2,3} \cdot$ Hideto Tawa $^{4} \cdot$ Fumie Kureha $^{4} \cdot$ Masaaki Wada $^{1} \cdot$ Nobuko Harada $^{5}$. \\ Yuki Ikeda $^{5} \cdot$ Kaemi Kimura $^{5} \cdot$ Naomi Kondo $^{5} \cdot$ Masashi Kanai $^{2,3} \cdot$ Ikko Kubo $^{2,3} \cdot$ Ryohei Yoshikawa $^{4} \cdot$ Yuichi Matsuda $^{4}$
}

Received: 19 October 2020 / Accepted: 8 January 2021 / Published online: 29 January 2021

(c) Springer Japan KK, part of Springer Nature 2021

\begin{abstract}
This study aimed to clarify the effects of the interruption of cardiac rehabilitation (CR) and refraining from going outside due to the COVID-19 pandemic on hemodynamic response and rating of perceived exertion (RPE) during exercise including differences by age in phase 2 CR outpatients. Among 76 outpatients participating in consecutive phase 2 CR in both periods from March to April and June to July 2020, which were before and after CR interruption, respectively, at Sanda City Hospital were enrolled. The inclusion criterion was outpatients whose CR was interrupted due to COVID-19. We compared the data of hemodynamic response and RPE during exercise on the last day before interruption and the first day after interruption when aerobic exercise was performed at the same exercise intensity in the $<75$ years group and $\geq 75$ years group. Fiftythree patients were enrolled in the final analysis. Post-CR interruption, peak heart rate increased significantly $(p=0.009)$ in the $<75$ years group, whereas in the $\geq 75$ years group, weight and body mass index decreased significantly $(p=0.009$, 0.011 , respectively) and Borg scale scores for both dyspnea and lower extremities fatigue worsened significantly (both, $p<0.001)$. CR interruption and refraining from going outside due to the COVID-19 pandemic affected the hemodynamic response, RPE during exercise and body weight in phase $2 \mathrm{CR}$ outpatients. In particular, patients aged $\geq 75$ years appeared to be placed at an increased risk of frailty.
\end{abstract}

Keywords COVID-19 $\cdot$ Phase 2 cardiac rehabilitation patient $\cdot$ Hemodynamic response $\cdot$ Rating of perceived exertion

\section{Introduction}

Coronavirus disease 2019 (COVID-19) caused by severe acute respiratory syndrome coronavirus 2 (SARS-CoV-2) may increase mortality in affected patients with cardiovascular disease (CVD) [1]. In addition, because it spreads from person to person via close contact, the delivery of cardiac

Kazuhiro P. Izawa

izawapk@harbor.kobe-u.ac.jp

1 Department of Rehabilitation, Sanda City Hospital, Sanda, Japan

2 Department of Public Health, Graduate School of Health Sciences, Kobe University, 10-2 Tomogaoka 7-chome Suma, Kobe 654-0142, Japan

3 Cardiovascular Stroke Renal Project (CRP), Kobe, Japan

4 Department of Cardiology, Sanda City Hospital, Sanda, Japan

5 Department of Nursing, Sanda City Hospital, Sanda, Japan rehabilitation (CR) is currently being hampered in many countries due to the COVID-19 pandemic [2,3].

The Japanese Association of Cardiac Rehabilitation announced guidelines to consider discontinuing phase 2 outpatient CR, particularly group exercise therapy, in endemic areas of COVID-19 in Japan. Outpatient phase 2 CR was actually interrupted in many areas, especially during the April-May state-of-emergency declaration. Furthermore, the government requested citizens to refrain from going outside. It is thus expected that physical activity performed during phase $2 \mathrm{CR}$ has decreased drastically. The problem of decreased physical activity due to COVID-19 is a global concern [4-7]. In fact, the introduction of a quarantine due to COVID-19 had a detrimental effect on the level of habitual physical activity performed by heart failure patients [8]. Reduced physical activity significantly lowers peak oxygen uptake $\left(\mathrm{VO}_{2}\right)$ [9], which is the gold standard indicator of cardiorespiratory fitness, and its decrease indicates a poor prognosis in patients with CVD [10, 11]. As well, the effects of COVID-19, such as weight gain, also increase the risk of 
heart disease [12]. As a result of staying at home, physical activity and exercise levels drastically decline while dietary habits remain unchanged or fail to offset this inactivity, thus producing a positive energy balance [13]. In fact, it was observed in northern Italy that obese outpatients gained significant weight 1 month after the beginning of the lockdown period there [14]. However, as it has also been reported that prolonged sedentary bouts were associated with worse frailty in CVD patients, it is possible that CVD patients may lose weight [15].

Thus, there is concern that interruption of CR or refraining from going outside may adversely affect the physical and cardiopulmonary function of outpatients participating in phase $2 \mathrm{CR}$. However, what effect it would have on hemodynamic response during exercise is unknown. It is important to clarify the effects of the interruption of phase $2 \mathrm{CR}$ and refraining from going outside on patients and to predict their condition at the resumption of CR and use this knowledge for exercise therapy and patient education. Above all, it is also useful as a measure against a recurrence of the pandemic.

Therefore, in this study, we hypothesized that the physical function of phase $2 \mathrm{CR}$ patients would decline due to the pandemic of COVID-19. However, the change in these functions might differ depending on age and should be considered separately in patients $<75$ years old and those $\geq 75$ years old [16]. Hence, the aim of this study was to clarify the effects of the COVID-19 pandemic on hemodynamic response, rating of perceived exertion (RPE) during exercise and body weight including differences by age in outpatients in whom phase $2 \mathrm{CR}$ was interrupted due to the pandemic.

\section{Methods}

\section{Study design and patients}

This was a retrospective, single-center, observational study. Seventy-six outpatients who participated in consecutive phase $2 \mathrm{CR}$ in the two periods from March to April and June to July 2020, which were before and after interruption, respectively, of CR at Sanda City Hospital were enrolled. The inclusion criterion was outpatients whose CR was interrupted due to COVID-19, and the exclusion criteria were patients with a change in exercise intensity and medications or who experienced cardiovascular events during the period of interruption. We compared the data obtained on the last day before interruption of CR with that obtained on the first day after resumption of $\mathrm{CR}$ when aerobic exercise was performed at the same exercise intensity. Patients' characteristics and clinical parameters including age, sex, body mass index, left ventricular ejection fraction, medical history, medications, CR interruption period, exercise intensity and parameters of usual aerobic exercise in CR were obtained from the electronic medical records by two physical therapists. A nurse questioned each of the patients to determine if they had decreased their level of exercise during the interruption of CR. The present study complied with the Declaration of Helsinki with respect to investigation in humans and was approved by the Ethics Committee of Sanda City Hospital (approval no. 2020006). Written informed consent was obtained from each patient.

\section{CR exercise program}

Aerobic exercise was performed based on the Guidelines for Rehabilitation in Patients with Cardiovascular Disease (JCS 2012) [17]. Exercise intensity is prescribed according to exercise at anaerobic threshold level, $40-60 \%$ of the peak $V \mathrm{O}_{2}, 40-60 \%$ of maximum heart rate (HR) or a Borg scale score of 12-13 or resting HR $+30 \mathrm{bpm}$ (resting HR $+20 \mathrm{bpm}$ for patients receiving $\beta$-blockers). Some patients underwent high-intensity interval training at $85 \%$ peak HR. Aerobic exercise was performed on a cycle ergometer or uphill treadmill, and the exercise time was $20 \mathrm{~min}$. All patients exercised while wearing a surgical or cloth mask.

\section{Hemodynamic assessment during CR}

The variables chosen for monitoring were HR and systolic blood pressure (SBP) as indicators of hemodynamic response. We measured the resting (Rest) and peak (Peak) HRs. For SBP, we measured the resting (Rest) SBP and the immediate post-exercise (Post) SBP. HR (Rest) was measured from lead II of a 3-lead electrocardiogram recorded using the limb lead method during exercise. All SBPs were measured with the patient in the sitting position. These measurements were obtained by one physical therapist and two nurses.

\section{Rating of perceived exertion (RPE) assessment during CR}

The RPEs for dyspnea and lower extremity fatigue were assessed using the Borg scale score [18] 10 min after the start of exercise and just before cooldown. The Borg scale score has been suggested to be a valid tool for monitoring and prescribing exercise intensity independent of sex, age, exercise modality, physical activity level and coronary artery disease status [19]. The same assessment panel was used for all patients to ensure minimal interindividual variability. 


\section{Statistical analysis}

Continuous variables are expressed as medians and interquartile ranges, categorical variables are expressed as percentages (numbers). Continuous variables were compared using the Mann-Whitney $U$ test and categorical data were compared using the $\chi^{2}$ test or the Fisher exact test, as appropriate. The Wilcoxon rank sum test was used to compare pre- and post-CR interruption. A $p$ value of $<0.05$ was considered to indicate statistical significance. All statistical analyses were performed with EZR (Saitama Medical Center, Jichi Medical University, Saitama, Japan), which is a graphical user interface for R (The R Foundation for Statistical Computing, Vienna, Austria). More precisely, it is a modified version of $\mathrm{R}$ commander designed to add statistical functions frequently used in biostatistics.

\section{Results}

Seventy-six outpatients participated in phase $2 \mathrm{CR}$ in the two periods from March to April and June to July 2020. Of them, 62 patients with interruption of CR were enrolled, with the exception of 14 patients who continued CR in individual 1:1 CR sessions. Patients with a change in exercise intensity $(n=6)$ or medications $(n=2)$ and patients admitted to hospital due to heart failure $(n=1)$ were excluded. Thus, 53 patients were included in the final analysis (Fig. 1). Table 1 presents their clinical characteristics. There were no significant differences between the patients in the $<75$ years group and the $\geq 75$ years group in sex, left ventricular ejection fraction, medical history, medications, $\mathrm{CR}$ interruption period, decreased exercise during $\mathrm{CR}$ interruption and exercise intensity at CR. Body weight, hemodynamics and RPE pre- and post-CR interruption can be compared in Table 2. Among the hemodynamic variables measured post-CR interruption, HR (Peak) showed significant increases $(p=0.001)$ in all patients. The peak Borg scale scores for both dyspnea and lower extremity fatigue also showed significant increases $(p=0.001,0.003$, respectively). Following post-CR interruption, the $<75$ years group experienced a significant increase in HR (Peak) ( $p=0.009$ ), whereas the $\geq 75$ years group experienced significant decreases in weight $(p=0.009)$ and BMI $(p=0.011)$ and worsening of the Borg scale scores for both dyspnea and lower extremities fatigue (both, $p<0.001$ ).

\section{Discussion}

Interruption of $\mathrm{CR}$ and refraining from going outside due to the COVID-19 pandemic affected the hemodynamic response, rating of perceived exertion during exercise and body weight in outpatients who were participating in phase $2 \mathrm{CR}$. Further, the impact of these findings was different between the group aged $<75$ and that $\geq 75$ years of age. The results in all patients showed that post-CR interruption, HR increased and Borg scale score worsened when assessed at the same intensity of exercise as that performed pre-CR interruption. However, age-specific examinations revealed that the findings in the outpatients under 75 years old and those over 75 years old were completely different.

Only HR (Peak) changed in the group under 75 years of age, whereas weight loss and worsening of RPE were observed in the group over 75 years old. The most likely cause of these changes are the decreases in exercise and physical activity. There have been reports of decreased physical activity due to the COVID-19 pandemic [5-7, 20]; and in the present study as well, $86.8 \%$ of patients responded that the amount of exercise they performed was reduced. A decrease in physical activity has various adverse effects. Cessation of regular exercise rapidly abolished all training
Fig. 1 Patient flow through the study. CR: cardiac rehabilitation; COVID-19: Coronavirus disease 2019
Outpatients who participated in phase $2 \mathrm{CR}$ in both March-April and June-July $2020(n=76)$

Outpatients who continued CR $(\mathrm{n}=14)$

Outpatients whose CR was interrupted due to the COVID-19 pandemic $(n=62)$

9 patients were excluded

Change in exercise intensity $(n=6)$

Change in medications $(\mathrm{n}=2)$

Hospitalization due to heart failure $(n=1)$

Patients included the analysis $(n=53)$

Age $<75(n=32)$

Age $\geq 75(n=21)$ 
Table 1 Clinical characteristics of the patients

\begin{tabular}{|c|c|c|c|c|c|}
\hline & All patients, $n=53$ & Age $<75$ years, $n=32$ & Age $\geq 75$ years, $n=21$ & $\chi^{2}$ value & $p$ value \\
\hline Age (years) & $73(67-76)$ & $68(61-72)$ & $76(76-80)$ & & $<0.001$ \\
\hline Male, $n(\%)$ & $41(77.4)$ & $23(71.9)$ & $18(85.7)$ & & 0.323 \\
\hline $\operatorname{LVEF}(\%)$ & $58.6(46.9-65.6)$ & $58.9(48.6-65.6)$ & $56.1(45.2-65.5)$ & & 0.547 \\
\hline \multicolumn{6}{|l|}{ Medical history } \\
\hline Previous MI, $n(\%)$ & $24(45.3)$ & $16(50.0)$ & $8(38.1)$ & 0.324 & 0.596 \\
\hline Angina pectoris, $n(\%)$ & $13(24.5)$ & $6(18.8)$ & $7(33.3)$ & 0.775 & 0.379 \\
\hline $\mathrm{CHF}, n(\%)$ & $23(43.4)$ & $15(46.9)$ & $8(38.1)$ & 0.121 & 0.728 \\
\hline Hypertension, $n(\%)$ & $35(66.0)$ & $23(71.9)$ & $12(57.1)$ & 0.658 & 0.417 \\
\hline Diabetes mellitus, $n(\%)$ & $27(50.9)$ & $18(56.2)$ & $9(42.9)$ & 0.453 & 0.501 \\
\hline \multicolumn{6}{|l|}{ Medications } \\
\hline Beta blocker, $n(\%)$ & $42(79.3)$ & $28(87.5)$ & $14(66.7)$ & & 0.090 \\
\hline $\mathrm{ACE}-\mathrm{I} / \mathrm{ARB}, n(\%)$ & $36(67.3)$ & $25(78.1)$ & $11(52.4)$ & 2.766 & 0.101 \\
\hline $\mathrm{CCB}, n(\%)$ & $20(37.7)$ & 13 (40.6) & $7(33.3)$ & 0.060 & 0.806 \\
\hline Diuretic, $n(\%)$ & $22(41.5)$ & $14(43.8)$ & $8(38.1)$ & 0.015 & 0.902 \\
\hline Period of CR interruption (days) & $77(63-92)$ & $70(59.6-98)$ & $84(70.0-91)$ & & 0.334 \\
\hline $\begin{array}{l}\text { Decreased exercise during CR inter- } \\
\text { ruption, } n(\%)\end{array}$ & $46(86.8)$ & $27(84.4)$ & $19(90.5)$ & & 0.690 \\
\hline Exercise intensity (watts) ${ }^{\mathrm{a}}$ & $50(40-60)$ & $50(40-60)$ & $50(40-60)$ & & 0.869 \\
\hline
\end{tabular}

Values shown are $n(\%)$, medians (interquartile ranges)

$A C E-I$ angiotensin-converting enzyme inhibitor, $A R B$ angiotensin II receptor blocker, $C C B$ calcium channel blocker, $C H F$ congestive heart failure, $C R$ cardiac rehabilitation, $L V E F$ left ventricular ejection fraction, $M I$ myocardial infarction

${ }^{\mathrm{a}}$ Only cycle ergometer $(n=49)$

Table 2 Patients' body weight, hemodynamics and RPE pre- and post-CR interruption

\begin{tabular}{|c|c|c|c|c|c|c|c|c|c|}
\hline & \multicolumn{3}{|c|}{ All patients, $n=53$} & \multicolumn{3}{|c|}{ Age $<75$ years, $n=32$} & \multicolumn{3}{|c|}{ Age $\geq 75$ years, $n=21$} \\
\hline & $\begin{array}{l}\text { Pre-interrup- } \\
\text { tion }\end{array}$ & $\begin{array}{l}\text { Post-interrup- } \\
\text { tion }\end{array}$ & $p$ value & $\begin{array}{l}\text { Pre-interrup- } \\
\text { tion }\end{array}$ & $\begin{array}{l}\text { Post-interrup- } \\
\text { tion }\end{array}$ & $p$ value & $\begin{array}{l}\text { Pre-interrup- } \\
\text { tion }\end{array}$ & $\begin{array}{l}\text { Post-interrup- } \\
\text { tion }\end{array}$ & $p$ value \\
\hline $\begin{array}{l}\text { Body weight } \\
\text { (kg) }\end{array}$ & $\begin{array}{l}65.1(58.6- \\
71.4)\end{array}$ & $\begin{array}{l}65.3(57.9- \\
71.5)\end{array}$ & 0.359 & $\begin{array}{l}67.2(59.8- \\
74.0)\end{array}$ & $\begin{array}{l}66.6(59.2- \\
73.3)\end{array}$ & 0.254 & $\begin{array}{l}61.7(57.4- \\
69.4)\end{array}$ & $\begin{array}{l}60.4(56.0- \\
67.9)\end{array}$ & 0.009 \\
\hline $\mathrm{BMI}\left(\mathrm{kg} / \mathrm{m}^{2}\right)$ & $\begin{array}{l}23.4(22.1- \\
25.5)\end{array}$ & $\begin{array}{l}23.4(21.6- \\
25.4)\end{array}$ & 0.239 & $\begin{array}{l}23.7(21.6- \\
26.4)\end{array}$ & $\begin{array}{l}23.8(22.5- \\
26.4)\end{array}$ & 0.367 & $\begin{array}{l}23.3(22.1- \\
24.9)\end{array}$ & $\begin{array}{l}22.9(22.2- \\
24.4)\end{array}$ & 0.011 \\
\hline Rest HR (bpm) & $64(61-71)$ & $67(60-76)$ & 0.114 & $64(58.8-70.3)$ & $\begin{array}{l}65.5(58.8- \\
75.3)\end{array}$ & 0.143 & $64(62.0-72.0)$ & $\begin{array}{l}71.0(60.0- \\
77.0)\end{array}$ & 0.324 \\
\hline $\begin{array}{c}\text { Peak HR } \\
\text { (bpm) }\end{array}$ & $101(91-109)$ & $104(92-112)$ & 0.001 & $\begin{array}{l}101.5(90.8- \\
109.3)\end{array}$ & $\begin{array}{l}104.5 \\
\quad(90-112)\end{array}$ & 0.009 & $\begin{array}{l}100.0(92.0- \\
108.0)\end{array}$ & $\begin{array}{l}103.0 \\
(95-110)\end{array}$ & 0.052 \\
\hline $\begin{array}{l}\text { Rest SBP } \\
(\mathrm{mmHg})\end{array}$ & $130(116-140)$ & $126(113-143)$ & 0.690 & $\begin{array}{l}131(121.5- \\
140)\end{array}$ & $\begin{array}{l}124.5(112.5- \\
143)\end{array}$ & 0.281 & $\begin{array}{l}128(115.0- \\
137)\end{array}$ & $\begin{array}{l}131.0(115.0- \\
147)\end{array}$ & 0.538 \\
\hline $\begin{array}{l}\text { Post-exercise } \\
\text { SBP } \\
(\mathrm{mmHg})\end{array}$ & $127(110-139)$ & $125(114-142)$ & 0.495 & $\begin{array}{l}121.5(105.8- \\
145.0)\end{array}$ & $\begin{array}{l}124.5(112.8- \\
142)\end{array}$ & 0.104 & $\begin{array}{l}128.0(112.0- \\
145.0)\end{array}$ & $\begin{array}{l}126.0(116.0- \\
137)\end{array}$ & 0.554 \\
\hline $\begin{array}{l}\text { Peak Borg } \\
\text { scale: dysp- } \\
\text { nea }\end{array}$ & $12(12-13)$ & $12.5(12-13)$ & 0.001 & $12(12.0-13)$ & $12(12.0-13)$ & 0.260 & $12(11.5-12)$ & $13(12.5-13)$ & $<0.001$ \\
\hline $\begin{array}{l}\text { Peak Borg } \\
\text { scale: lower } \\
\text { extremities }\end{array}$ & $12(12-13)$ & $12.5(12-13)$ & 0.003 & $12(12-13)$ & $12.5(12.0-13)$ & 0.440 & $12(12-12)$ & $13.0(12.5-13)$ & $<0.001$ \\
\hline
\end{tabular}

$C R$ cardiac rehabilitation; $B M I$ body mass index; $H R$ heart rate; $R P E$ rating of perceived exertion; $S B P$ systolic blood pressure. Values shown are medians (interquartile ranges) 
adaptations for cardiorespiratory fitness and cardiometabolic health within one month after cessation [21]. Even if exercise is not completely interrupted, reductions of more than one- to two-thirds in training frequency and/or duration reduce exercise capacity. Furthermore, despite maintaining training frequency and the duration of exercise, a decrease of one- to two-thirds in exercise training intensity reduces both $\mathrm{VO}_{2 \max }$ and submaximal endurance time [22]. There are several reports of an increase in HR occurring at the same exercise intensity after exercise interruption in subjects $<75$ years of age. Increases in HR that occur with tapering, reduced training and complete cessation of training may reflexively arise to counteract the reduction in ventricular filling and maximal stroke volume that occurs when the volume of blood decreases [22, 23]. However, there was no significant increase in HR (Peak) in our $\geq 75$ years group. In this regard, the decline in $\beta$-receptor density with age may be due to a slowing heart rate response at moderate exercise intensity with low catecholamine levels [24].

In contrast, the $\geq 75$ years group experienced weight loss and deterioration of the Borg scale score at the same exercise intensity, suggesting concern that these are indications of an increased risk of frailty. Weight loss is a typical characteristic of frailty [25], and one of the causes of weight loss is a decrease in skeletal muscle mass [26]. Physical inactivity and a sedentary life lead to specific alterations in the skeletal muscle that contribute to insulin resistance, impairment of oxidative function and rapid hypotrophy [27]. These changes in the muscle pathophysiology usually take place after a couple of weeks, but they can also occur more quickly in older people [27]. The changes in the Borg scale score in the $\geq 75$ years group was greater than the value reported as the minimally clinically important difference in both dyspnea and lower extremity fatigue [28]. The worsening of the Borg Scale score for lower extremity fatigue may reflect this decrease in skeletal muscle mass and may also indicate a decrease in skeletal muscle metabolism [29]. Furthermore, as the Borg scale score is useful as a marker of impending decline in mobility-intact older adults [30], and it decrease is a serious issue with regard to the prognosis of patients with cardiac disease. The $\geq 75$ years group had performed independent activities of daily living and was able to exercise at $50 \mathrm{~W}$, the same level as that in the $<75$ years group. The percentage of the outpatients who reported that their physical activity decreased was also not significantly different from that of the $<75$ years group. Nonetheless, the factors leading to this result were the functional reserve capacity of the heart and skeletal muscle decline with age [31]. Several studies have proved that the losses in strength and function due to detraining are higher in the elderly than in younger people [27, 32].

Currently, a system to provide phase $2 \mathrm{CR}$ during the COVID-19 pandemic is under consideration $[2,3]$. The present study suggested that more careful intervention is needed with a focus on the decline of physical function, especially in patients aged 75 years and older.

\section{Study limitations}

Several limitations of this study need to be acknowledged. First, this was a single-center, retrospective study comprising a very small number of patients. Second, detailed physical activity and exercise during CR interruption were not investigated. As we were not able to actually measure skeletal muscle mass and $\mathrm{VO}_{2}$, quantitative evaluation will be required in a future study. Third, Table 1 shows that the $77.4 \%$ of patients were men and the authors found no difference between men and women in the present study. However, it is well known that women were less likely to perform physical activity and that sarcopenia strongly affected postmenopausal women [33]. Thus, gender-related differences, it needs to do more research work in the future trial. Finally, the parameters obtained from usual exercise therapy (HR and SBP) may reduce the overall quality of the present assessment. However, in the current situation where exercise tests in hospitals are difficult to perform due to the COVID19 pandemic, these parameters measured during usual exercise may be useful as the easiest and safest indicators that can be obtained.

\section{Conclusion}

Interruption of $\mathrm{CR}$ and refraining from going outside due to the COVID-19 pandemic affected the hemodynamic response, rating of perceived exertion during exercise and body weight in outpatients participating in phase $2 \mathrm{CR}$. The effect was particularly large on patients aged 75 and over and appeared to place these patients at an increased risk of frailty.

Acknowledgements The authors would like to thank all of the participating patients in Sanda City Hospital. We thank the staff members of Kobe University who collaborated in this study. This study was also benefitted by the support and encouragement of Sae Ono of the Faculty of Health Sciences, Kobe University, and Hiroto Ogi, Kodai Ishihara, Masahiro Kitamura, Yuji Kanejima, Masato Ogawa, and Shinichi Shimada, all of the Graduate School of Health Sciences, Kobe University. We also thank Dr. Minato Nakazawa, Department of Public Health, Graduate School of Health Sciences, Kobe University, for statistical support of the present study.

\section{Compliance with ethical standards}

Conflict of interest The authors declare that they have no conflict of interest. 


\section{References}

1. Ferrari R, G. Pasquale GD, Rapezzi C, (2020) Commentary: what is the relationship between Covid-19 and cardiovascular disease? Int J Cardiol 310:167-168

2. Besnier F, Gayda M, Nigam A, Juneau M, Bherer L (2020) Cardiac rehabilitation during quarantine in COVID-19 pandemic: challenges for center-based program. Arch Phys Med Rehabil 101(10):1835-1838

3. Kemps HMC, Brouwers RWM, Cramer MJ, Jorstad HT, Kluiver EP, Kraaijenhagen RA, Kuijpers PMJC, Linde MR, Melker E, Rodrigo SF, Spee RF, Sunamura M, Vromen T, Wittekoek ME (2020) Recommendations on how to provide cardiac rehabilitation services during the COVID-19 pandemic. Neth Heart J 28:387-390

4. Peçanha T, Gressler KF, Roschel H, Gualano B (2020) Social isolation during the COVID-19 pandemic can increase physical inactivity and the global burden of cardiovascular disease. Am J Physiol Heart Circ Physiol 318:H1441-H1446

5. Hall G, Laddu DR, Phillips SA, Lavie CJ, Arena R (2020) A tale of two pandemics: how will COVID-19 and global trends in physical inactivity and sedentary behavior affect one another? Prog Cardiovasc Dis. https://doi.org/10.1016/j.pcad.2020.04.005

6. Tison GH, Avram R, Kuhar P, Abreau S, Marcus GM, Pletcher MJ, Olgin JE (2020) Worldwide effect of COVID-19 on physical activity: a descriptive study. Ann Intern Med. https://doi.org/10.7326/ M20-2665

7. Lippi G, Henry BM, Sanchis-Gomar F (2020) Physical inactivity and cardiovascular disease at the time of coronavirus disease 2019 (COVID-19). Eur J Prev Cardiol 27:906-908

8. Vetrovsky T, Frybova T, Gant I, Semerad M, Cimler R, Bunc V, Siranec M, Miklikova M, Vesely J, Griva M, Precek J, Pelouch R, Parenica J, Belohlavek J (2020) The detrimental effect of COVID-19 nationwide quarantine on accelerometer-assessed physical activity of heart failure patients. ESC Heart Fail 7(5):2093-2097

9. Bowden Davies KA, Sprung VS, Norman JA, Thompson A, Mitchell KL, Halford JCG, Harrold JA, Wilding JPH, Kemp GJ, Cuthbertson DJ (2018) Short-term decreased physical activity with increased sedentary behavior causes metabolic derangements and altered body composition: effects in individuals with and without a first-degree relative with type 2 diabetes. Diabetologia 61:1282-1294

10. Arena R, Myers J, Abella J, Pinkstaff S, Brubaker P, Kitzman PDW, Peberdy MA, Bensimhon D, Chase P, Guazzi M (2011) Cardiopulmonary exercise testing is equally prognostic in young, middleaged and older individuals diagnosed with heart failure. Int J Cardiol 151:278-283

11. Tashiro H, Tanaka A, Ishii H, Motomura N, Arai K, Adachi T, Okajima T, Iwakawa N, Kojima H, Mitsuda T, Hirayama K, Hitota Y, Hayashi M, Furusawa K, Yoshida R, Imai H, Ogawa Y, Kawaguchi K, Murohara T (2020) Reduced exercise capacity and clinical outcomes following acute myocardial infarction. Heart Vessels 35:1044-1050

12. Mattioli AV, Puviani MB, Nasi M, Farinetti A (2020) COVID-19 pandemic; the effects of quarantine on cardiovascular risk. Eur J Clin Nutr 74:852-855

13. Martinez-Ferran M, Guía-Galipienso F, Sanchis-Gomar F, ParejaGaleano H (2020) Metabolic impacts of confinement during the COVID-19 pandemic due to modified diet and physical activity habits. Nutrients 12:1549

14. Pellegrini M, Ponzo V, Rosato R, Scumaci E, Goitre I, Benso A, Belcastro S, Crespi C, Michieli FD, Ghigo E, Broglio F, Bo S (2020) Changes in weight and nutritional habits in adults with obesity during the "Lockdown" period caused by the COVID19 virus emergency. Nutrients 12(7):2016

15. Kehler DS, Clara I, Hiebert B, Stammers AN, Hay J, Schultz A, Arora RC, Tangri N, Duhamel TA (2019) The association between patterns of physical activity and sedentary time with frailty in relation to cardiovascular disease. Aging Med (Milton) 2:18-26

16. Ouchi Y, Rakugi H, Arai H, Akishiro M, Ito H, Toba K, Kai I (2017) Redefining the elderly as aged 75 years and older: proposal from the joint committee of Japan gerontological society and the Japan geriatrics society. Geriatr Gerontol Int 17:1045-1047

17. JCS Joint Working Group (2014) Guidelines for rehabilitation in patients with cardiovascular disease (JCS 2012). Circ J 78:2022-2093

18. Borg GA (1982) Psychophysical bases of perceived exertion. Med Sci Sports Exerc 14:377-381

19. Scherr J, Wolfarth B, Christle JW, Pressler A, Wagenpfeil S, Halle M (2013) Associations between Borg's rating of perceived exertion and physiological measures of exercise intensity. Eur J Appl Physiol 113:147-155

20. Hamer M, Kivimäki M, Gale CR, Batty GD (2020) Lifestyle risk factors, inflammatory mechanisms, and COVID-19 hospitalization: a community-based cohort study of 387,109 adults in UK. Brain Behav Immun 87:184-187

21. Nolan PB, Keeling SM, Robitaille CA, Buchanan CA, Dalleck LC (2018) The effect of detraining after a period of training on cardiometabolic health in previously sedentary individuals. Int J Environ Res Public Health 15:2303

22. Neufer PD (1989) The effect of detraining and reduced training on the physiological adaptations to aerobic exercise training. Sports Med 8:302-320

23. Zavorsky GS (2000) Evidence and possible mechanisms of altered maximum heart rate with endurance training and tapering. Sports Med 29:13-26

24. Birnbaumer P, Traninger H, Borenich A, Falgenhauer M, ModreOsprian R, Harpf H (2020) Heart rate performance curve is dependent on age, sex, and performance. Front Public Health 8:98

25. Bortz WM 2nd (2002) A conceptual framework of frailty: a review. J Gerontol A Biol Sci Med Sci 57:M283-M288

26. Fried LP, Tangen CM, Walston J, Newman AB, Hirsch C, Gottdiener J, Seeman T, Tracy R, Kop WJ, Burke G, McBurnie MA (2001) Frailty in older adults: evidence for a phenotype. J Gerontol A Biol Sci Med Sci 56:M146-M156

27. Stefano VD, Battaglia G, Giustino V, Gagliardo A, D'Aleo M, Giannini O, Palma A, Brighina F (2020) Significant reduction of physical activity in patients with neuromuscular disease during COVID-19 pandemic: the long-term consequences of quarantine. J Neurol. https ://doi.org/10.7326/M20-2665

28. Khair RM, Nwaneri C, Damico RL, Kolb T, Hassoun PM, Mathai SC (2016) The minimal important difference in Borg dyspnea score in pulmonary arterial hypertension. Ann Am Thorac Soc 13:842-849

29. Stendardi L, Grazzini M, Gigliotti F, Lotti P, Scano G (2005) Dyspnea and leg effort during exercise. Respir Med 99:933-942

30. Simonsick EM, Glynn NW, Jerome GJ, Shardell M, Schrack JA, Ferrucci L (2016) Fatigued, but not frail: perceived fatigability as a marker of impending decline in mobility-intact older adults. J Am Geriatr Soc 64:1287-1292

31. Goldspink DF (2005) Ageing and activity: their effects on the functional reserve capacities of the heart and vascular smooth and skeletal muscles. Ergonomics 48:1334-1351

32. Coswig VS, Barbalho M, Raiol R, Vecchio FBD, Ramirez-Campillo R, Gentil P (2020) Effects of high vs moderate-intensity intermittent training on functionality, resting heart rate and blood pressure of elderly women. J Transl Med 18:88

33. Sciomer S, MoscucciMaffei Gallina Mattioli FSSAV (2019) Prevention of cardiovascular risk factors in women: the lifestyle paradox and stereotypes we need to defeat. Eur J Prev Cardiol 26:609-610

Publisher's Note Springer Nature remains neutral with regard to jurisdictional claims in published maps and institutional affiliations. 